Wemyss, C. , Gibson, J. and Ryan, K. (2019) A case of idiopathic First Bite Syndrome responding to carbamazepine. Oral Surgery, 12(3), pp. 243-247.

There may be differences between this version and the published version. You are advised to consult the publisher's version if you wish to cite from it.

This is the peer reviewed version of the following article:

Wemyss, C. , Gibson, J. and Ryan, K. (2019) A case of idiopathic First Bite Syndrome responding to carbamazepine. Oral Surgery, 12(3), pp. 243-247. (doi:10.1111/ors.12407)

This article may be used for non-commercial purposes in accordance with Wiley Terms and Conditions for Self-Archiving.

http://eprints.gla.ac.uk/179632/

Deposited on: 13 February 2019

Enlighten - Research publications by members of the University of Glasgow http://eprints.gla.ac.uk/ 
MR. CALLUM WEMYSS (Orcid ID : 0000-0003-0107-0361)

Article type : Case Report

\title{
A case of idiopathic First Bite Syndrome responding to carbamazepine.
}

\author{
Callum Wemyss BDS (Hons) MFDS RCPS(Glasg) \\ Dental Core Trainee 3 \\ Oral Surgery/Oral Medicine \\ Glasgow Dental Hospital and School \\ 378 Sauchiehall Street
}

Glasgow

G2 3JZ

John Gibson PhD BDS MB ChB FRCP(Glasg) FDS(OM)RCPS(Glasg) FFDRCS(Irel)

Professor of Oral Medicine

Institute of Dentistry

University of Aberdeen

Cornhill Rd

Aberdeen

AB25 2ZR

This article has been accepted for publication and undergone full peer review but has not been through the copyediting, typesetting, pagination and proofreading process, which may lead to differences between this version and the Version of Record. Please cite this article as doi: 10.1111 /ors.12407

This article is protected by copyright. All rights reserved. 


\section{Kevin Ryan BDS MB BCh BAO FDS(OM)RCPS(Glasg)}

Consultant in Oral Medicine (Clinical Lead)

Honorary Senior Clinical Lecturer

Glasgow Dental Hospital and School

378 Sauchiehall Street

Glasgow

G2 3JZ

\section{Correspondence to}

Callum Wemyss

Glasgow Dental Hospital and School

378 Sauchiehall Street

Glasgow

G2 3JZ

Email: callumwemyss@nhs.net

Phone: 01412119600

First Bite Syndrome (FBS) is a painful condition which classically presents as severe pain in the preauricular region, initiated on the first bite of a meal. It is usually associated with a history of upper neck surgery or tumour of the parotid salivary gland or parapharyngeal space (PPS). Some propose FBS arises from damage to, or resection of, the cervical sympathetic trunk resulting in loss of sympathetic innervation to the parotid salivary gland. Idiopathic FBS has been reported only a handful of times in the literature. We present the case of a 51-year-old male, urgently referred to the Department of Oral Medicine, with a three-week history of severe, sharp, unilateral pain from the right angle of mandible, intensity described as ' $20 / 10$ ', occurring only on the first bite of eating. This would diminish over two minutes. Clinical examination revealed tenderness over the right condylar neck and angle of mandible only. FBS was suspected and the patient immediately started on carbamazepine. An urgent MRI displayed no abnormalities of the TMJ, PPS, trigeminal nerve or parotid gland. Restorative Dentistry review confirmed no odontogenic/occlusal cause and on review, four months later the patient reported complete resolution of symptoms on $200 \mathrm{mg}$ of

This article is protected by copyright. All rights reserved. 
carbamazepine three times daily. This case highlights the importance of taking a thorough pain history. Patients with symptoms of FBS and no history of surgery to the neck should have an MRI to rule out parotid gland or PPS tumour. Carbamazepine can be successful in treating idiopathic FBS and can resolve symptoms completely.

Keywords: First bite syndrome, parotid gland, carbamazepine, head and neck surgery, temporomandibular pain.

\section{Introduction}

First Bite syndrome, first described by Netterville in 1998, is severe parotid pain elicited on the first bite of a meal without any prodromal symptoms. ${ }^{1}$ This is not to be confused with the definition used by Haubrich in 1986 who used the term to describe a completely different collection of symptoms including an inability to swallow with retrosternal pain on the first bite of meal. ${ }^{2}$ FBS usually diminishes seconds or minutes after the first bite of a meal, can deter patients from eating and has been reported to affect quality of life (QoL). ${ }^{3}$ It is thought to be accentuated by particular gustatory stimuli (acids, sour, spicy or sweet foods or drinks), salivation and some even say the thought of food. ${ }^{4,5}$

It is typically seen in patients who have had surgery to the neck or a tumour of the parotid salivary gland or parapharyngeal space (PPS). Netterville's 1998 case series presented 49 patients who were treated with surgery for vagal paragangliomas. ${ }^{1}$ First bite syndrome was reported postoperatively in eight of the nine patients who had sympathetic trunk resection. Since then, FBS has also been implicated post-operatively in cases of cervical lymph node dissection, ${ }^{6}$ deep lobe parotidectomy, TMJ joint replacement, ${ }^{8}$ bimaxillary osteotomy, ${ }^{9}$ resection of the stylohyoid ligament in Eagle's Syndrome ${ }^{10}$ carotid bifurcation and/or internal carotid artery surgery such as carotid endarterectomy or ligation. ${ }^{11}$ In a case series by Kawashima FBS was reported post-operatively in 9 of 29 patient who underwent resection of parapharyngeal tumours. ${ }^{12}$ Following surgery it usually takes a few weeks but can sometimes take several months for symptoms to develop. In addition, there has been one recent case of Eagle's syndrome presenting with symptoms of FBS preoperatively. ${ }^{13}$

Tumours reported to have caused symptoms of first bite syndrome include tumours of the parapharyngeal space (synovial sarcoma), ${ }^{14}$, deep poles of the parotid (adenoid cystic carcinoma, squamous cell carcinoma and mucoepidermoid carcinoma), ${ }^{15-17}$ and submandibular gland (adenoid cystic carcinoma). ${ }^{18}$ Caution must therefore be exercised with patients experiencing symptoms of FBS. Guss et al reported an adenoid cystic carcinoma of the submandibular gland which was not clinically or radiographically apparent until 18 months after initial presentation of FBS symptoms. ${ }^{18}$

This article is protected by copyright. All rights reserved. 
More recently Maheer et al described a male, with no surgical history, diagnosed with FBS nine years previously who had a CT scan six years later which revealed a mass consistent with a lipoma in the right parotid region. ${ }^{16}$ After no improvement in pain with various drugs and an enlarging mass on the right face he was diagnosed with a squamous cell carcinoma of the parotid. It is unlikely he had the malignancy for nine years and the exact aetiology was concluded as uncertain. The only report of a benign tumour presenting as itself as FBS is an Osteoid Osteoma of the temporal bone. ${ }^{19}$

There have been a number of post-operative cases which have also been associated with Horner's syndrome which can also result from damage to the sympathetic trunk. Frey's, Harlequin's and Pour Tour du Petit are other examples of different symptom complexes resulting from injury to sympathetic innervation. ${ }^{20}$

To date there have only been four published reports (one case series and three case reports) on patients with symptoms of FBS with no history of surgery and no detectable tumour on Magnetic Resonance Imaging (MRI). ${ }^{21-24}$

\section{Case Report}

We present the case of a 51-year-old male, with no history of head or neck surgery, urgently referred to the Oral Medicine Department with 'jaw pain'. The patient presented with a three week history of severe, sharp, unilateral pain from the right angle of mandible, intensity described as '20/10' on a visual analogue scale (VAS), occurring only on the first bite of eating a meal. This pain would always diminish over two minutes and after it had subsided he could finish the meal without any further pain. The pain radiated to the ear and was accentuated by sweet foods. Prior to the referral the patient had been managed by his dentist for a temporomandibular disorder including conservative advice, analgesia, hard acrylic splint and jaw exercises.

Medically the patient had ischaemic heart disease and had a myocardial infarction 11 years ago. In addition, he had type II diabetes which was diet controlled. His most recent HbA1c was 72 . He had no habits, history of trauma to the face and was not aware of clenching or grinding his teeth. He wore an upper cobalt chrome partial denture.

Clinical examination revealed tenderness over the right condylar neck and angle of mandible only. This was consistent with the position of the right parotid gland. There was no clicking, locking or crepitus of the temporomandibular joints (TMJs) and the joints were not tender to palpate. Mouth opening was unaffected. Furthermore, there were no enlarged salivary glands and no palpable cervical lymphadenopathy. Intraorally, the patient had a number of missing teeth and significantly

This article is protected by copyright. All rights reserved. 
none posterior to the LR5 (lower right first premolar) on the lower arch. The UR6 (upper right first molar) and UR7 (upper right second molar) had large amalgam restorations. None of the teeth provided positive responses to ethyl chloride (cold testing) but gave normal range positive responses to the electric pulp test. This suggested, but did not confirm, both molars were vital.

An orthopantomogram (OPT) was taken (figure one) to rule out any odontogenic cause, or indeed, any other gross pathology. The OPT showed a retained root in the upper right quadrant, possible caries in the UR6 and LL4 (lower left first premolar) and severe bone loss due to periodontitis but nothing to account for the patient's severe pain.

FBS was suspected and the patient immediately started on carbamazepine $100 \mathrm{mg}$ once a day and his general medical practitioner asked to increase this as per response. An urgent MRI was carried out displaying some minor age-related changes but no abnormalities of the TMJ, PPS, parotid and trigeminal nerve.

The patient was reviewed after a month reporting an improvement on $100 \mathrm{mg}$ carbamazepine in the morning and 200mg at night. At this point a dedicated TMJ MRI sequence was carried out this showed some stretching of the disc on both sides but normal relocation and no other abnormalities. Restorative Dentistry review confirmed no odontogenic or occlusal cause to the patient's pain and on review, in the Oral Medicine Department, four months later the patient reported complete resolution of symptoms on $200 \mathrm{mg}$ of carbamazepine three times daily. The patient will be closely followed up with the plan to eventually taper off the carbamazepine.

\section{Figure 1 OPT which includes the jaws, dentition, maxillary sinuses and TMJ.}

\section{Discussion}

Nettervile suggested that this syndrome is secondary to the loss of sympathetic innervation to the parotid gland. ${ }^{1}$ This would result in denervation hypersensitivity of the sympathetic receptors that control the myoepithelial cells in the parotid gland. With oral intake, the secreted parasympathetic neurotransmitter cross-stimulates the sympathetic receptors, causing an autonomic imbalance. This leads to supramaximal contraction of the myoepithelial cells and pain on the parotid region on the first bite. Sympathetic innervation should not be damaged in idiopathic cases of FBS therefore this could suggest a different pathophysiology. There have been a number of cases following surgery involving ablation of the sympathetic trunk that did not develop first bite syndrome. Conversely, a deep lobe parotidectomy, due to a pleomorphic adenoma, where there was no reported damage to sympathetic structures and no ligation of the external carotid artery developed FBS. ${ }^{12}$ These both

This article is protected by copyright. All rights reserved. 
complicate the theory and support the fact that the pathophysiology of FBS is still not well understood.

Chiba et al reported 14 patients with idiopathic FBS who presented to an orofacial clinic over three years. ${ }^{21}$ Of these patients, nine had poorly controlled diabetes. Postprandial pain (pain after mealtime) was also suffered in six of the nine patents. Postprandial pain has not been reported in any previous case of post-operative or tumour-related FBS. Chiba et al also postulates that the pathophysiology is different and for that reason they refer to idiopathic first bite syndrome as Idiopathic Parotid Pain (IPP) in their paper. There have been a small number of idiopathic FBS cases which have been bilateral, again, hinting at a systemic rather than local mechanism in these cases. In the case, reported in this manuscript, the patient had poorly controlled type II diabetes but reported no postprandial pain. Diabetic neuropathy perhaps plays a role in idiopathic FBS but is unlikely to be the cause. Chiba et al highlighted that idiopathic FBS appeared to be more common in males and suggests that this could be due to the fact men more frequently develop diabetic neuropathy. Other than Chiba's case series there have only been three other cases of idiopathic FBS reported in the literature..$^{22-24}$

There have been a number of suggestions that FBS, specifically post-operative FBS, will eventually resolve without any treatment over a period of months to years. ${ }^{25}$ In a retrospective review of 53 patients undergoing surgery to the neck, 16 developed FBS postoperatively. Symptoms resolved in 11 of these patient's over a period of months to two years without any treatment and the 5 remaining patients were still symptomatic at five years. Due to limited data and studies regarding idiopathic FBS it is unclear if symptoms would completely resolve without any treatment.

A number of different treatments have been used and suggested for the management of first bite syndrome. The most common treatment appears to be pharmacological management. Non-steroidal anti-inflammatories and codeine-based analgesia have proved ineffective in all cases. Other drugs used have included carbamazepine (with or without amitriptyline), pregabalin and neurotrophic agents. ${ }^{20}$ In the idiopathic case, which we present, the patient's pain was significantly better at one month of carbamazepine and completely resolved by five months. Stoopler and Elmuradi reported an idiopathic case of FBS which responded to botulinum toxin (botox) injections into the parotid gland after not responding to $150 \mathrm{mg}$ oxcarbamazepine twice a day and $1800 \mathrm{mg}$ gabapentin daily. ${ }^{22}$ To date, botox has been reported effective, in reducing pain in all cases it has been used. ${ }^{3,26-29}$ Typically the effects last three-four months at which point patients require repeat injections, however, it has been suggested that due to the fact that symptoms of FBS can resolve with time it could be a useful temporising measure. ${ }^{27}$ There have been no side effects reported such as facial paralysis or dry mouth associated with intraglandular injections of botox.

This article is protected by copyright. All rights reserved. 
In non-idiopathic cases, dietary modification, such as asking the patient to stick to 'bland' foods, has been suggested as a successful treatment. ${ }^{1}$ Chiba reported that one of the of the eight idiopathic FBS patients responded to dietary modification with the rest responding to pregabalin or neurotrophic agents. $^{21}$

Stellate ganglion blocks have been used in another idiopathic case by Kurokawa et al to effect and acupuncture has been used to varying effect. ${ }^{23,30}$ Radiotherapy has also been cited as a successful treatment in patients who developed FBS following major oncologic neck surgery. This is perhaps due to damage to parotid parenchyma from the radiation. In a study of 499 patients who had surgery to the parotid, PPS or infratemporal fossa (ITF) between 1992-2010, 9.6\% of patients developed FBS. Of the 499 patients, 47 of these patients had a history of head or neck radiotherapy and none went on to develop FBS. ${ }^{31}$

Surgery to remove tumours causing FBS have proven successful in resolving symptoms but surgery to treat first bite syndrome in post-operative cases, such as tympanic neurectomy, has proven unsuccessful and has certain risks attached. ${ }^{5,26}$ There has only been one reported case of resolution with laser tympanic plexus ablation, however the follow-up for this case was only two months. ${ }^{32}$

\section{Conclusions}

This case highlights the importance of taking a thorough pain history. FBS should not be confused with temporomandibular pain which could lead to inappropriate management. Patients with symptoms of FBS and no history of surgery to the neck should have an MRI to rule out a parotid, PPS or ITF tumour. Diabetes could play a part in idiopathic cases of FBS and this should be further investigated. Carbamazepine can be successful in treating idiopathic FBS and can resolve symptoms completely.

\section{Acknowledgements}

The authors declare they did not receive any funding for this report. The authors declare they have no conflicts of interest.

This article is protected by copyright. All rights reserved. 


\section{References}

1. Netterville JL, Jackson CG, Miller FR, Wanamaker JR, Glasscock ME. Vagal paraganglioma: a review of 46 patients treated during a 20-year period. Arch Otolaryngol Head Neck Surgery 1998;124:1133-1140.

2. Haubrich WS. The first bite syndrome. Henry Ford Hosp Med J 1986;34:275-278.

3. Lee BJ, Lee JC, Lee, YO, Wan, SG, Kim HJ. Novel Treatment of First Bite syndrome using Botulinum Toxin Type A. Head \& Neck 2009;31:989-993.

4. Abdeldaoui A, Oker N, Duet M, Cunin G, Huy TB. First Bite Syndrome: A little known complication of upper cervical surgery. Eur Ann Otorhinolaryngol Head Neck Dis 2013;130:123-129.

5. Chiu AG, Cohen JI, Buningham AR, Andersen PE, Davidson BJ. First Bite Syndrome: A complication of surgery involving the parapharyngeal space. Head \& Neck 2002;24:996-999.

6. Costa TP, de Araujo CE, Filipe J, Pereira AM. First bite syndrome in oncologic patients. Eur Arch Otorhinolaryngol 2011;268:1241-1244.

7. Houle A, Mandel L. First Bite Syndrome After Deep Lobe Parotidectomy: Case Report. J Oral Maxillofac Surg 2014;72:1475-1479.

8. Alwanni N, Altay MA, Baur DA, Quereshy FA. First Bite Syndrome After Bilateral Temporomandibular Joint Replacement: Case Report. J Oral Maxillofac Surg 2016;74:480488.

9. Scholey AL, Suida MI. First bite syndrome after bimaxillary osteotomy: case report. Br J Oral Maxillofac Surg 2015;53:561 - 563.

10. Hardin FM, Xiao R, Burkey BB. Surgical management of patient with Eagle syndrome Am J Otolaryngo 2018;39: 481-484.

11. Albasri H, Eley KA, Saeed NR. Chronic pain related to first bite syndrome: report of two cases. Br J Oral Maxillofac Surg 2011;49:154-156.

12. Kawashima $Y$, Sumi $T$, Sugimoto $T$, Kishimoto $S$. First bite syndrome: a review of 29 patients with parapharyngeal space tumor. Auris Nasus Larynx 2008;35:109-113.

13. Gauthier B, Segolene G, Bruno C. First-bite syndrome and Eagle syndrome. J Oral Med Oral Surg 2018;24:36-39.

14. Lieberman SM, Har-El G. First bite syndrome as a presenting symptom of a parapharyngeal space malignancy. Head \& Neck 2011;33:1539-1541.

15. Deganello A, Meccariello G, Busoni M, Franchi A, Gallo O. First bite syndrome as presenting symptom of parapharyngeal adenoid cystic carcinoma. J Laryngol Otol. 2011;125:428-431.

16. Masood MM, Giosia MD, Hackman TG. Chronic atypical first bite syndrome and primary squamous cell carcinoma of the parotid. Head \& Neck 2018;40:E82-E86.

17. Diercks GR, Rosow DE, Prasad M, et al. A case of preoperative "first bite syndrome" associated with mucoepidermoid carcinoma of the parotid gland. Laryngoscope 2011;121:760-762.

18. Guss J, Ashton-Sager AL, Fong BP. First bite syndrome caused by adenoid cystic carcinoma of the submandibular gland. Laryngoscope 2012;123:426-428.

This article is protected by copyright. All rights reserved. 
19. Hidaka H, Yamauchi D, Fujishima F, Watanabe M, Kato Y, Nomura Kazuhiro et al. Osteoid osteoma of the temporal bone manifesting as first bite syndrome and meta-analysis combined with osteoblastoma. Eur Arch Otorhinolaryngol 2017:274;607-616.

20. Laccourreye O, Werner A, Garcia D, Malinvaud D, Huy TB, Bonfils P. First bite syndrome. Eur Ann Otorhinolaryngol 2013;130:269-273.

21. Chiba M, Hirotani H, Takahashi T. Clinical Features of Idiopathic Parotid Pain Triggered by the First Bite in Japanese Patients with Type 2 Diabetes: A case study of 9 patients. Pain Research and Treatment 2018; 2018:1-6.

22. Stoppler ET, Elmuradi S. Idiopathic First Bite Syndrome. J Oral Maxillofac Surg 2016; 74: 872874.

23. Kurokawa H, Takezaki T, Kawaguchi R, Nakao M, Sato N, Unetani H et al. Idiopathic first bite syndrome treated with repeated stellate ganglion blocks: a case report. Journal of Japan Society of Pain Clinicians 2010;17:17-20.

24. Chiba M, Hirotani H, Echigo S. Bilateral idiopathic first bite syndrome: a case report. Journal of The Japanese Stomatological Society 2012;61:327-330.

25. Avincsal MO, Hiroshima Y, Shinomiya H, Shinymiya H, Otsuki N, Nibu K. First bite syndrome An 11-year experience. Auris Nasus Larynx 2017;44:302-305.

26. Ali MJ, Orloff LA, Lusting LR, Eisele DW. Botulinum Toxin in the treatment of first bite syndrome. Otolaryngol Head Neck Surg 2008;139:742-743.

27. Sims JR, Suen JY. First bite syndrome: Case report of 3 patients treated with botulinum toxin and review of other treatment modalities. Head Neck 2013;35:E288-E291.

28. Ghosh A, Mirza N. First Bite Syndrome: Our Experience with Intraparotid Injections with Botulinum Toxin Type A. Larngoscope 2016; 126:104-107.

29. Costales-Marcos M, Alvarez FL, Fernandez-Vanes L, Gomez J, Llorente JL. Treatment of the First Bite syndrome. Acta Otorrinolaringol Esp 2017;68:284-288.

30. Fiorini FR, Santoroa RM, Cristofaro G, Buongioro A, Mannelli G, Picconi M et al. Potential use of acupuncture in the treatment of first bite syndrome. Am J Otolarngol 2015; 36:484-487

31. Linkov G, Morris LGT, Shah JP, Kraus DH. First Bite Syndrome: Incidence, Risk Factors, Treatment, and outcomes. Laryngoscope 2012;122:1773-1778.

32. Amin N, Pelser A, Weighill J. First bite syndrome: our experience of laser tympanic plexus ablation. J Larnngol Otol 2014; 166-168.

This article is protected by copyright. All rights reserved. 


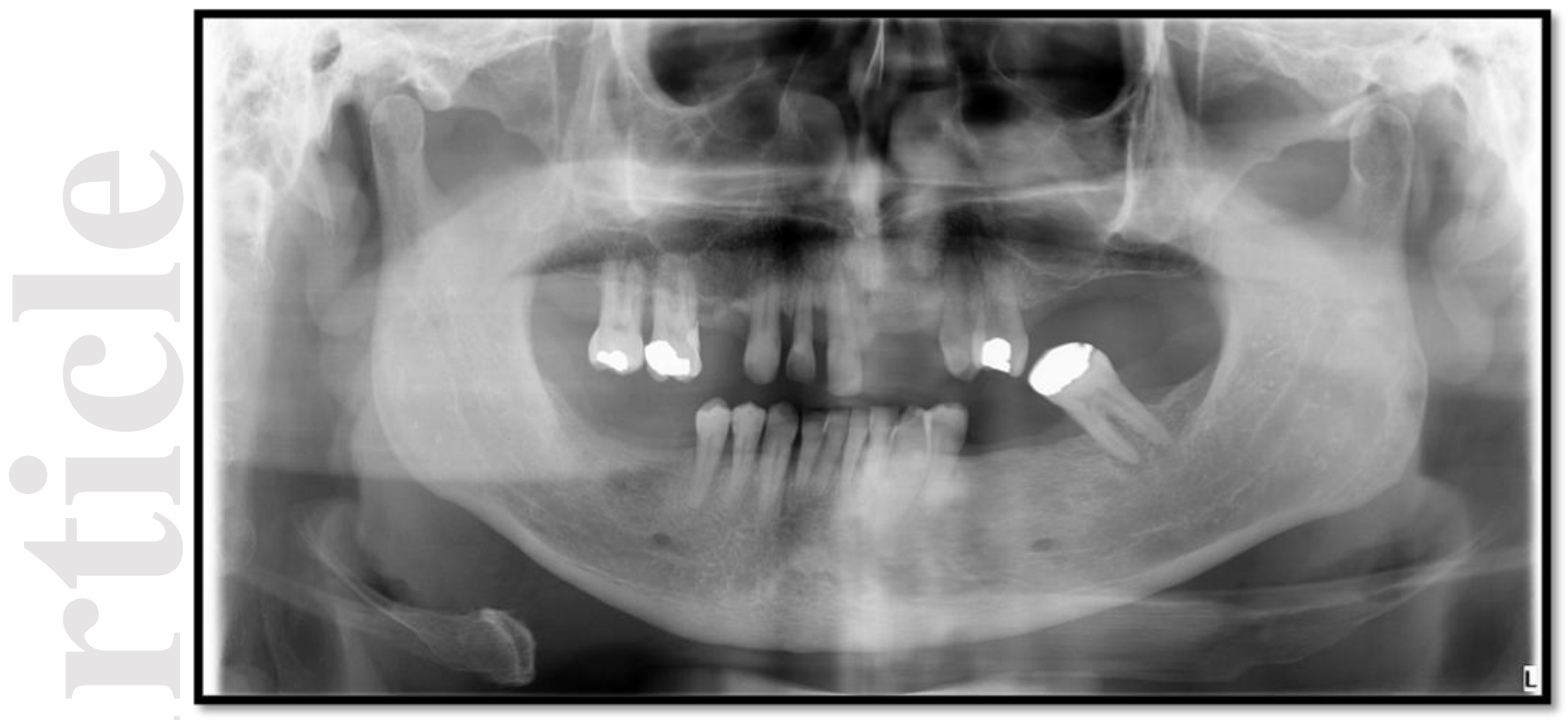

Figure 1 OPT which includes the jaws, dentition, maxillary sinuses and TMJ.

This article is protected by copyright. All rights reserved. 